УДК 550.34

\title{
МЕХАНИЧЕСКИЙ ИМПУЛЬС - ВАЖНЕЙШАЯ ХАРАКТЕРИСТИКА СЕЙСМИЧЕСКИХ ПРОЦЕССОВ
}

\author{
Мишин С. В., Панфилов А. А., Хасанов И. М. \\ ФГБУН Северо-Восточный комплексный научно-исследовательский институт \\ им. Н. А. Шило ДВО РАН, г. Магадан \\ E-mail:mishin@neisri.ru
}

\begin{abstract}
На основе данных о Спитакском землетрясении 1988 г. рассматривается модель удара при перемещении крупного блока горных пород, альтернативная широко распространенной модели упругой отдачи. Сопоставляются динамические параметры Спитакского землетрясения 7 декабря 1988 г., полученные по ортодоксальной модели (упругой отдачи), с оценками динамики по ударной модели (удар при перемещении блока горных пород). Предлагается модель земной коры, сформированной тяготением Земли, - геологические массивные тела опираются друг на друга и выдерживают вес вышележащих пород. В результате разрушения опорной площадки блок горных пород смещается, при торможении блока формируется пакет сейсмического излучения - распространяется механический импульс, приобретенный блоком при перемещении. Рассмотрена номограмма, позволяющая оценивать значения параметров процесса землетрясения - сместившейся массы, механического импульса, давления волнового фронта. Магнитуда процесса имеет размерность механического импульса, а балл сотрясения - размерность давления.
\end{abstract}

Ключевые слова: удар, механический импульс, давление фронта волны, вес блока горных пород, ньютоновская сила.

DOI: $10.34078 / 1814-0998-2020-2-3-9$

\section{ВВЕДЕНИЕ}

Процесс землетрясения в современной литературе описывается главным образом на основе гипотезы упругой отдачи (Костров, 1975; Аки, Ричардс,1983; Касахара,1985). Мы отказались от гипотезы упругой отдачи, поскольку не видим в земных недрах материалов, способных аккумулировать упругую энергию, а также знаем, что наиболее мощный механизм, действующий на принципе упругой отдачи, - арбалет - уступает по мощности простому обвалу горных пород, наконец, описание процессов проводится для невесомой среды. В результате характеристикой интенсивности процесса остается физически неясная величина - магнитуда, а действие излучения на материальные конструкции - балл. Ни магнитуда, ни балл не имеют ясного физического смысла.

Еще в 1915 г. Б. Б. Голицын отказался от представления о связи процесса землетрясения 2020 с упругостью горных пород. Анализируя материалы обследования Сарезского землетрясения 1911 г., он писал: «...результат представляет особый интерес, так как из него вытекает следствие первостепенной важности.

Не касаясь совершенно вопроса, отчего произошел самый обвал горы, мы можем с большою степенью вероятности утверждать, что этот обвал был не следствием, а причиной того землетрясения 18 февраля 1911 г., которое было отмечено на стольких сейсмических станциях.

Мы имеем в этом землетрясении любопытнейший и, если я не ошибаюсь, первый случай, когда мы наперед знаем величину энергии, освобожденной в эпицентре землетрясения.

Кроме того, это землетрясение выделяется из числа обычных землетрясений еще и той интересной особенностью, что для него гипоиентр и эпицентр совпадают» (Голицын, 1960. C. 365-370).

Не соглашаясь с гипотезой упругой отдачи, мы полагаем, что землетрясение есть следствие 
удара при перемещении крупного блока горных пород под действием тяготения Земли (Мишин, 2013).

\section{АНАЛИЗ ПРОЦЕССА СПИТАКСКОГО ЗЕМЛЕТРЯСЕНИЯ 1988 Г.}

Инструментальные данные, полученные при регистрации этого события, проанализированы в работе (Кондорская и др.,1991). Сейсмограммы получены всей мировой сетью сейсмических станций (в том числе более 30 станций Кавказа). Положение очага землетрясения определено по 11 методикам. Время в очаге определено от 741 21.7 до 741 36.0; широта - от 40.83 до 41.10 с. ш.; долгота - от 44.13 до 44.36 в. д.; глубина очага от 3 до 15 км. «Отмечается, что периоды в продольной волне по короткопериодной аппаратуре меняются от 1 до $4 \mathrm{c}, T_{\text {сp }}=1.7 \mathrm{c}$; по среднепериодной - от 5 до $12 \mathrm{c}, T_{c p .}^{c p}=7.1 \mathrm{c}$; по длиннопериодной от 6 до $12 \mathrm{c}, T_{c p .} \stackrel{c p .}{=} 8.4 \mathrm{c}$ 》 (Кондорская и др.,1991. С. 66).

К динамическим параметрам очага авторы (Кондорская и др.,1991) отнесли магнитуду, сейсмический момент и механизм очага: $\mathrm{MPV}=6.8$, $\mathrm{MLV}=6.9$; сейсмический момент от $0.56 \cdot 10^{19}$ до $4.2 \cdot 10^{19}$.

К. Аки и Р. Ричардс так формулируют определение величины сейсмического момента:

$\ll M_{0}=\mu U A=$ модуль сдвига $\times$ средняя подвиж$\kappa a \times$ площадь разрыва. Мы называем эту величи- ну $M_{0}$ сейсмическим моментом. Это, вероятно, наиболее фундаментальный параметр, который можно использовать, чтобы измерить силу землетрясения, вызванного подвижкой по разрыву», (1983. С. 55). С нашей точки зрения, $M_{0}$ - сопротивление перемещению невесомого тела на расстояние $U$; эта величина не имеет отношения к процессу излучения из очага.

Методика расчетов механизма очага была разработана А. В. Введенской, которая имела мужество отказаться от технологии, получившей широкое распространение (1984). Физический смысл нодальных плоскостей и осей сжатия и растяжения остается неясным.

\section{МОДЕЛЬ ЗЕМНОЙ КОРЫ}

Действием тяготения планеты земные недра сложены химически связанными геологическими телами. Каждое тело опирается на другие тела и выдерживает вес лежащих выше объектов. Опорные площадки тел формируют каркас, или скелет, некоторого объема недр, который обеспечивает устойчивость конструкции. Средняя плотность этого объема обыкновенно меньше плотности образцов пород, складывающих его, за счет трещин и полостей, включенных в объем.

На рис. 1 приведен сейсмический разрез МОВОГТ, полученный при работах по глубинному сейсмическому зондированию профиля $3 Д В$ (Сальников и др., 2014). Рисунок 1,a иллюстри-
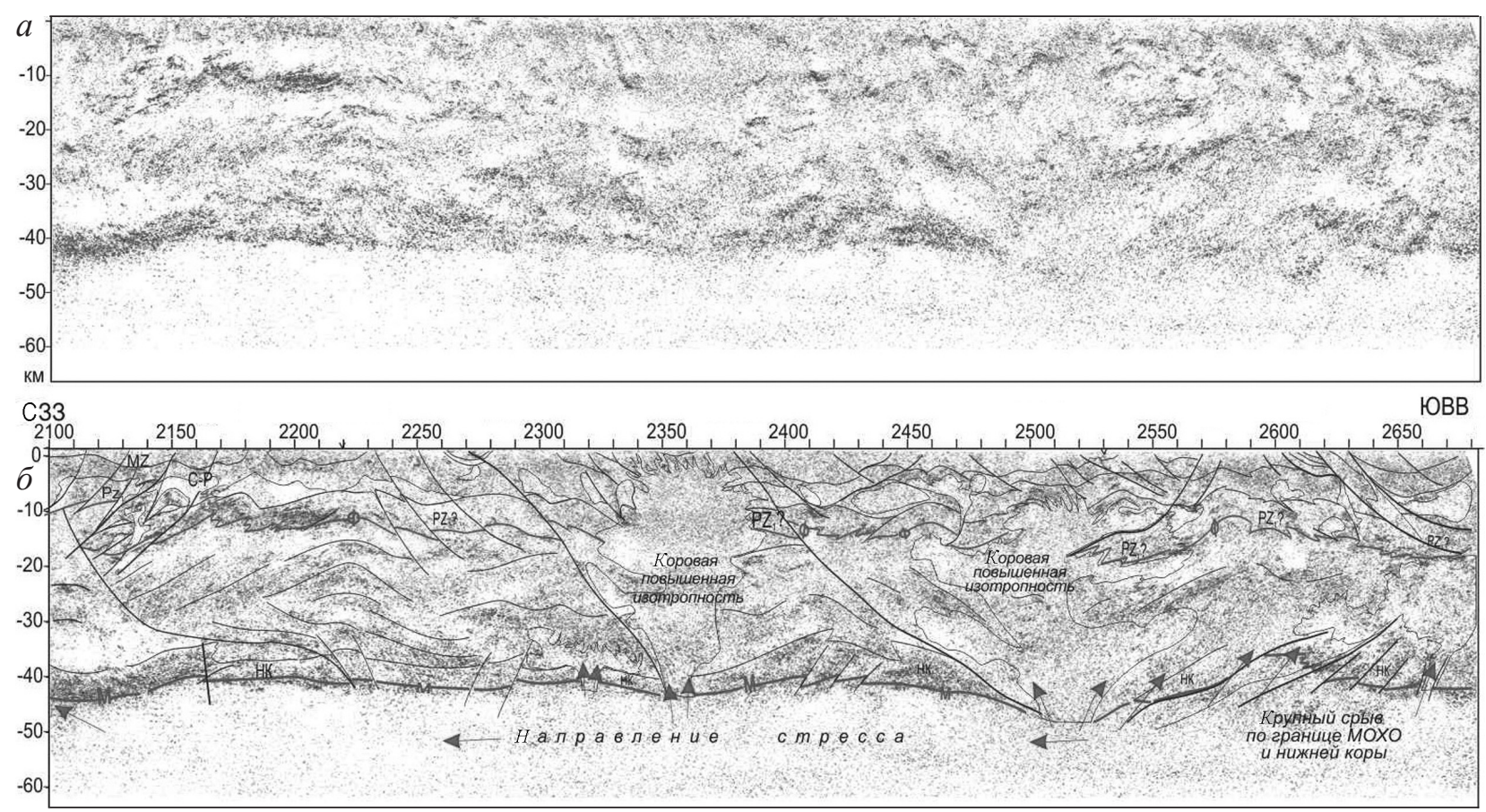

Puc. 1. Интерпретация геофизических данных участка профиля ГСЗ ЗДВ (Иньяли-Дебинский синклинорий): $a$ - разрез МОВ-ОГТ; $\sigma$ - схема строения земной коры этого участка

Fig. 1. Interpretation of geophysical data from the section of the NHS 3DV profile (Inyali-Debinsky synclinorium): $a-\mathrm{RWM}-\mathrm{CDM}$ section; $\sigma$ - earth's crust structure in this section 
рует множество отражающих площадок, заполняющих недра участка. Отражающие площадки, по-видимому, связаны с границами геологических тел, с трещинами и полостями, имеющимися в земных недрах. Сгущения отражающих площадок с учетом других геофизических данных интерпретируются в виде границ, разделяющих структуры земной коры (рис. 1, б). Наиболее четко выделяется обычно граница Мохоровичича подошва земной коры.

Напряженное состояние земных недр определяется главным образом весом геологических тел. На глубине 40 км весовое давление может превышать 120 тыс. т/м², да и на глубине 10 км эта величина около 30 тыс. т/м². Такие давления пока достигаются техническими средствами в редчайших случаях. Кроме того, предполагается, что температура среды на глубине подошвы земной коры достигает $700^{\circ} \mathrm{C}$. При таких температурах прочность горных пород падает, но в условиях гидростатического давления материалы обычно упрочняются. Во всяком случае, очевидно, что состояние пород, складывающих геологические тела на глубинах, характерных для очагов землетрясений, весьма специфично, их нельзя надежно сравнивать с имеющимися техническими характеристиками, полученными в лаборатории.

Можно предположить, что граница Мохоровичича, наиболее надежно выделяемая на всех геофизических разрезах, соответствует практически полному разрушению геологических тел, формирующих недра. Земная кора «плавает» в стеклообразной или смолообразной массе, подкоровом субстрате. Вес каждого столба геологических тел, опирающихся на Мохо и складывающих этот столб, может отличаться от веса других столбов из-за разной плотности материалов, а также за счет полостей и трещин, разделяющих геологические тела. Эти различия в весе отдельных элементов среды определяют форму дневной поверхности участка- менее плотные структуры выделяются в виде возвышенностей на фоне долин, связанных с более плотными структурами.

Проведем мысленный эксперимент, следуя Х. Рамбергу (Рамберг, 1985), который моделировал тяготение с помощью центрифуги. Поместим в центрифугу тела разной плотности и формы и зададим достаточную скорость вращения. Центробежная сила, имитирующая тяготение, распределит массы подобно тяготению Земли. Внешний слой вещества окажется плотным, часть тел будет раздавлена, на внутренней поверхности, аналогичной дневной поверхности, будут «плавать» легкие компоненты. В «разрезе» возможны инверсии плотности, т. е. наличие тел меньшей плотности под более тяжелыми структурами, но вероятность существования крупных инверсион- ных тел мала - плотность материала с глубиной будет увеличиваться, что обычно и наблюдается в геофизических разрезах. В природе материал, по-видимому, распределяется подобным образом. Средняя плотность пород растет с глубиной, менее плотные структуры «плавают» в субстрате, формируя особенности рельефа дневной поверхности.

\section{МОДЕЛЬ ПРОЦЕССА ЗЕМЛЕТРЯСЕНИЯ}

Сейсмоприемники регистрируют удары при торможении перемещающихся масс. Обвалы горных пород, происходящие на дневной поверхности, непременно сопровождаются более или менее интенсивными пакетами сейсмического излучения. Напротив, далеко не каждое землетрясение (даже тектоническое) сопровождается обвалами или оползнями на дневной поверхности. Мы полагаем, что землетрясение есть удар при торможении смещающейся массы горных пород после того, как разрушится опорная площадка, удерживавшая блок в покое (в поле тяготения Земли). Энергия процесса определяется простым соотношением $E=M g \Delta h$, где $M$ - масса сместившегося блока, $g$ - ускорение свободного падения, $\Delta h$ - разность между первоначальным и конечным положением центра масс блока при перемещении. Потенциальная энергия $E$ в процессе перемещения блока переходит в кинетическую, блок приобретает импульс $\mathrm{P}=\operatorname{sqrt}(\mathrm{E}$. $2 \cdot \mathrm{M})=\mathrm{M} \cdot \operatorname{sqrt}(2 \cdot \mathrm{g} \cdot \Delta \mathrm{h})$. По мере торможения массы этот импульс отдается среде в виде пакета сейсмического излучения (Мишин, 2013).

Процесс разрушения опорной площадки, повидимому, локализован в небольшой по размерам области. Объем смещающегося блока и со-

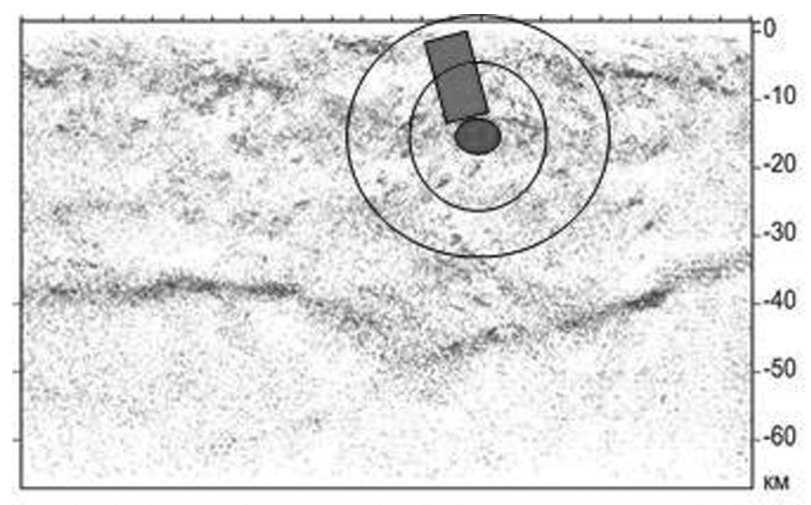

Pис. 2. Модель процесса землетрясения. Опорная площадка (кружок) разрушается, блок горных пород (прямоугольник) перемещается, в результате удара генерируется сейсмическое излучение

Fig. 2. Earthquake process model. The support area (circle) is destroyed, the rock block (rectangle) shifts, and seismic radiation is generated as a result of the shock 
ответствующая масса определяются размерами и связями неустойчиво расположенных масс горных пород. В качестве предвестников сильного землетрясения можно рассматривать появление слабых толчков и акустического излучения из области разрушающейся площадки, т. е. на глубинах, соответствующих будущему очагу. Хорошо известны процессы просадки построенных зданий, в глубоких шахтах отмечаются горные удары - это, с нашей точки зрения, процессы одного ряда. Рисунок 2 иллюстрирует схему процесса землетрясения.

Сейсмическая активность - дискретный процесс, сопровождающий преобразования блоковой структуры земных недр. Землетрясение удар при перемещении блока горных пород в новое положение.

\section{ХАРАКТЕРИСТИКИ ПРОЦЕССА ЗЕМЛЕТРЯСЕНИЯ ПО УДАРНОЙ МОДЕЛИ}

Мы пытаемся перейти от специфической сейсмологической терминологии к терминам механики, основываясь на экспериментальных результатах, - простые опыты позволяют сделать вывод, что сейсмическое излучение при ударах и взрывах представляет собой распространение механического импульса в сплошной среде, а квадрантное распределение знаков определяется ударом тела, не отрывающегося от «грунта» (Мишин, 2016).

Схема процесса землетрясения представляется простой: массивное тело, опирающееся на другие тела, в результате разрушения опоры перемещается под действием собственного веса.
В процессе удара - торможения движения, тело отдает среде приобретенную кинетическую энергию и соответствующий механический импульс. Именно импульс формирует пакет сейсмического излучения, распространяющийся далее в пространстве. Импульс имеет две формы - поступательную (количество движения) и вращательную (момент количества движения), приобретаемую при поворотах тела. Пакет излучения распространяется со скоростью продольных волн Р и со скоростью поперечных волн $\mathrm{S}$ в виде шаровых слоев с увеличивающимися радиусами. На поверхности шарового слоя происходит передача импульса невозбужденным частицам среды, при этом действуют ньютоновсие силы $\mathrm{F}=\mathrm{dP} / \mathrm{dt}$, которые определяют давление фронта волны.

Для наглядных грубых оценок динамических параметров процесса мы предложили номограмму, связывающую эти величины для сейсмического события (Мишин, 2013) (рис. 3).

Левая часть номограммы позволяет анализировать источник излучения - связь излученного импульса с массой сместившегося тела, с энергией процесса. Соотношение между этими величинами мы уже рассматривали: $\mathrm{P}=\operatorname{sqrt}(2 \mathrm{ME})$ или $\mathrm{P}=\mathrm{M} \cdot \operatorname{sqrt}(2 \mathrm{gh})$. Масса $\mathrm{M}$, энергия Е и импульс $\mathrm{P}$ - важнейшие понятия механики, для которых известны законы сохранения, поэтому равенства выполняются при любых масштабах событий. Левая часть номограммы построена в соответствии с этим соотношением: проводя отрезок прямой через точки, выбранные на шкале М и на шкале E (или h), получим на шкале Р значение импульса, излученного при ударе массы М (сме-

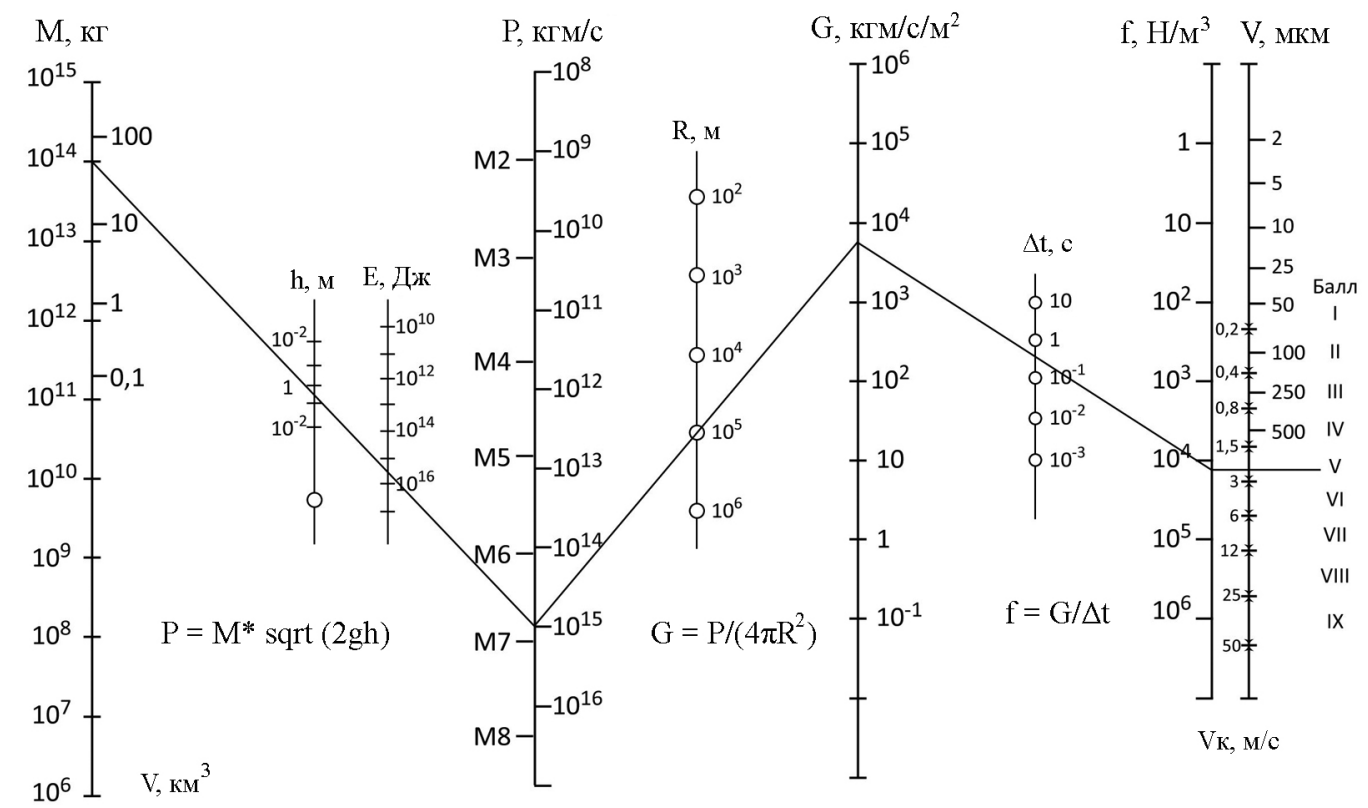

Puc. 3. Номограмма для оценки параметров процесса землетрясения

Fig. 3. Nomograph for evaluating the earthquake process parameters 
стившейся с высоты h). Массы М приобретают кинетическую энергию вследствие преобразования потенциальной энергии, которая к моменту начала процесса могла быть представлена гравитационной, химической, упругой или электромагнитной формой.

На номограмме построена дополнительная шкала $h$, использующая соотношение $\mathrm{E}=\mathrm{Mgh}$, где $\mathrm{E}$ - энергия, $\mathrm{M}$ - масса, g - ускорение силы тяжести, $\mathrm{h}$ - высота падения массы. Пользуясь этой шкалой, можно определять значение отданного импульса, исходя из значений массы ударяющего тела и высоты его падения: $\mathrm{P}=\mathrm{M} \sqrt{\mathrm{gh}}$. Ось $\mathrm{P}$ мы градуируем также в значениях магнитуды или энергетического класса - как указывалось ранее, фундаментальная характеристика сейсмического события - величина импульса, излученного из источника.

Следующая часть номограммы - характеристика сферического расхождения сейсмического излучения. Плотность импульса на единицу площади волнового фронта уменьшается пропорционально квадрату расстояния от источника: $G=P / 4 \pi R^{2}$. Это соотношение, вероятно, хорошо описывает распространение сейсмического излучения в изотропной среде. В случае удара неизбежно существование некоторой преимущественной направленности излучения, схемы изосейст землетрясений также редко бывают круговыми. Будем надеяться, что наше представление о сферическом расхождении сигналов не внесет слишком больших ошибок в грубую схему процесса. Для того, чтобы получить значение плотности импульса на фронте излучения на расстоянии $\mathrm{R}$ от источника, проведем прямую через соответствующие значения на осях $\mathrm{P}$ и $\mathrm{R}$ : прямая отсечет на шкале $\mathrm{G}$ значение, соответствующее плотности импульса на фронте излучения на расстоянии R от источника.

Третья часть номограммы оценивает значение среднего сейсмического давления $\mathrm{f}$ фронта излучения как функцию продолжительности сейсмического сигнала, передающего импульс в сплошной среде. Зависимость сейсмического давления от продолжительности сигнала $\Delta \mathrm{t}$ построена в номограмме в виде $\mathrm{f}=\mathrm{G} / \Delta \mathrm{t}$. Продолжительность сигнала мы оцениваем четвертью периода первого вступления - временем роста давления. Разумеется, реальные процессы могут вызывать другие давления, и такое приближение может оказаться неточным. Давление f, определенное по номограмме, соответствует среднему значению ньютоновской силы, действующей на $1 \mathrm{~m}^{2}$ поверхности среды, удаленной на расстояние $\mathrm{R}$ от источника. Значение давления определяется пересечением со шкалой $f$ прямой, проведенной из значения $\mathrm{G}$ на соответствующей шкале через значение $\Delta \mathrm{t}$, выбранное на шкале продолжительности сигнала.

Таким образом, проводя три отрезка прямых, мы количественно оцениваем основные параметры сейсмического события: излученный импульс, плотность импульса на поверхности фронта излучения на выбранном расстоянии, сейсмическое давление фронта, если заданы другие параметры процесса: значение массы, тормозящейся в источнике, энергии, которой обладала ударяющая масса, продолжительность процесса возбуждения. Эти части номограммы отражают физические соотношения между параметрами процесса.

Последние вертикальные оси номограммы позволяют оценить эмпирические характеристики сотрясения «среднего грунта», вызванные возбужденным излучением. Для установления связи между шкалой сейсмического давления и нормативной шкалой сейсмической интенсивности MSK-64 были использованы оценки колебательной скорости при промышленных взрывах (Справочник..., 1974).

Для оценки параметров процесса Спитакского землетрясения воспользуемся значением магнитуды события $\mathrm{M}=6.8$. Такая магнитуда соответствует значению переданного в среду импульса $\mathrm{P} \approx 10^{15}$ кгм/с. На одном из участков Спитакского разлома образовался уступ высотой 2 м со смещением по горизонтали тоже на 2 м (Певнев, 2003). Предположим, что масса блока сместилась по высоте на 2 м. Тогда эта масса приближается к $10^{14}$ кг, а объем блока около 80 км$^{3}$. Приобретенный при торможении блока импульс на расстоянии 100 км определит плотность импульса около $10^{4} \mathrm{\kappa}$ м/с/ $\mathrm{M}^{2}$. Разделив эту величину на продолжительность сигнала, получим среднее значение давления фронта продольной волны. Среднее значение периода колебаний в продольной волне по (Кондорская и др., 1991) составляет 1.7 с , т. е. $\Delta \mathrm{t} \approx 0.4$ с. Тогда среднее давление $\mathrm{f} \approx 2.5 \cdot 10^{4} \mathrm{H} / \mathrm{M}^{2}$, что соответствует 5-6 баллам по шкале MSK-64.

Таким образом, Спитакское землетрясение явилось результатом удара при перемещении блока горных пород объемом около $80 \mathrm{kм}^{3}$ на 2 м по вертикали; на расстоянии 100 км от очага ньютоновские силы создали давление $2.5 \times$ $10^{4} \mathrm{H} / \mathrm{M}^{2}$. Это привело к сотрясению объектов в 5-6 баллов, что хорошо согласуется с данными, приведенными в статье (Гедакян и др.,1991). Разброс значений положения гипоцентра, вероятно, связан с тем обстоятельством, что очаг отличается от точки - это поверхность соударения крупного блока при его торможении; станции фиксировали вступления от ближайших к ним точек этого протяженного очага. 
В 1971 г. на границе Якутии с Магаданской областью произошло Оймяконское (Артыкское) землетрясение, магнитуда которого оценивалась значениями от 5.9 до 7.1, т. е. близкое по интенсивности к Спитакскому (Кочетков, Козьмин, 1976). Вследствие малой населенности территории Артыкское землетрясение не привело к человеческим жертвам и серьезным экономическим потерям. Сеть станций в регионе не позволила получить подробных инструментальных сведений, однако макросейсмика позволяет заключить, что эффекты Артыкского землетрясения соответствуют результатам Спитакского толчка - в Сусумане на расстоянии 180 км от эпицентра сотрясения оценивались в 6 баллов.

\section{ЗАКЛЮЧЕНИЕ}

Сопоставление моделей процесса землетрясения в виде разрядки упругих напряжений и удара сместившейся массы горных пород позволяет отметить очевидную ясность ударной модели в сравнении со сложной терминологией модели упругой. Весь процесс описывается средствами классической механики, получаемых инструментально данных оказывается достаточно для оценки основных параметров процесса. Результаты простых расчетов не противоречат макросейсмическим наблюдениям.

\section{ЛИТЕРАТУРА}

Аки К., Ричардс П. Количественная сейсмология. М. : Мир, 1983. 364 c.

Введенская A. В. Сейсмодинамика. М. : Наука, 1984. $140 \mathrm{c}$.
Гедакян Э. Г., Голинский Г. Л., Папалашвили В. Г., Хромеикая Е. А., Шебалин Н. В. Спитакское землетрясение 7 декабря 1988 г., карты изосейст // Землетрясения в СССР в 1988 году. М. : Наука, 1991. С. 74-86.

Голииын Б. Б. О землетрясении 18 февраля 1911 года // Избр. тр. М. : Изд. АН СССР, 1960. Т. 2. C. $365-370$.

Касахара К. Механика землетрясений. М. : Мир, 1985. $264 \mathrm{c}$.

Кондорская Н. В., Вандышева Н. В., Захарова А. И. Спитакское землетрясение 7 декабря 1988 г. Инструментальные данные. Землетрясения в СССР в 1988 г. М. : Наука, 1991. С. 60-74.

Костров Б. В. Механика очага тектонического землетрясения. М. : Наука, 1975.172 с.

Кочетков В. М., Козьмин Б. М. Оймяконское землетрясение 1971 г. и его афтершоки // Сейсмичность и глубинное строение Сибири и Дальнего Востока. Владивосток, 1976. С. 61-67.

Мишин С. В. О физике сейсмических процессов. Эксперименты и модели. Lambert Academic Publishing, 2013. $196 \mathrm{c}$.

Мишин С. В. Об экспериментах в сейсмологии // Науч. журн. «Содружество». 2016. № 3. Ч. 2. С. 105109.

Певнев $A . K$. Пути к практическому прогнозу землетрясений. М. : ГЕОС, 2003. 152 с.

Рамберг $X$. Сила тяжести и деформации в земной коре. М. : Недра, 1985. 399 с.

Сальников А. С., Старосельиев В. С., Соболев П. Н. Отчет о результатах работ по объекту «Создание опорного геолого-геофизического профиля 3 ДВ (Северо-Восточный участок)». Росгеолфонд ТФГИ по Дальневосточному федеральному округу, 2014.

Справочник по инженерной геологии / под ред. М. В. Чуринова. М. : Недра, 1974. 408 с.

Поступила в редакиию 05.10.2018 г.

Поступила после доработки 16.04.2019 2.

\title{
MECHANICAL IMPULSE AS THE PRIMARY CHARACTERISTIC OF SEISMIC PROCESSES
}

\author{
S. V. Mishin, A. A. Panfilov, I. M. Khasanov
}

North-East Interdisciplinary Scientific Research Institute n. a. N. A. Shilo, FEB RAS, Magadan

Based on the data from the 1988 Spitak earthquake, the article presents a model of the shock during the shift of a large block of rocks, an alternative to the widely spread elastic recoil model. The dynamic parameters of the Spitak earthquake of December 7, 1988, obtained by the orthodox (elastic recoil) model, are compared with the estimates of the shock model dynamics (impact when a block of rocks shifts). A model of the earth's crust, formed by the earth's gravity, is proposed: massive geological bodies lean on each other and withstand the weight of overlying rocks. As a result of the support platform destruction, the rock block is displaced. When the block is decelerated, a seismic radiation package is formed: a mechanical impulse, acquired by the block during its shift, is propagated. The authors discuss the nomograph that permits to estimate the values of the earthquake process parameters (displaced mass, mechanical impulse, wave front pressure). The process magnitude has the mechanical impulse dimensionality; the shake, that of pressure.

Keywords: shock, mechanical impulse, wave front pressure, rock block weight, Newtonian force. 


\section{REFERENCES}

Aki, K.; Richards, P., 1983, Quantitative Seismology, Moscow, Mir [In Russian].

Engineering Geology Reference, 1974, Ed. M. V. Churinov, Moscow, Nedra [In Russian].

Ghedakyan, E. G.; Golinsky, G. L.; Papalashvili, V. G., Khrometskaya, Ye. A.; Shebalin, N. V., 1991, Spitak Earthquake of December 7, 1988, Isoseismic Maps, Earthquakes in the USSR in 1988, Moscow, Nauka, 7486 [In Russian].

Golitsyn, B. B., 1960, On the Earthquake of February 18, 1911, Selected Works, Moscow, AS USSR, 2, 365370 [In Russian].

Kasahara, K., 1985, Earthquake Mechanics, Moscow, Mir [In Russian].

Kochetkov, V. M.; Koz'min, B. M., 1976, Oymyakon Earthquake of 1971 and Its Aftershocks, Seismicity and Deep Structure of Siberia and the Far East, Vladivostok, 61-67 [In Russian].

Kondorskaya, N. V.; Vandysheva, N. V.; Zakharova, A. I., 1991, Spitak Earthquake of December 7, 1988, In- strumental Records, Earthquakes in the USSR in 1988, Moscow, Nauka, 60-74 [In Russian].

Kostrov, B. V., 1975, Mechanics of the Tectonic Earthquake Focus, Moscow, Nauka [In Russian].

Mishin, S. V., 2013, On the Physics of Seismic Processes, Experiments and Models, Lambert Academic Publishing [In Russian].

Mishin, S. V., 2016, On Experiments in Seismology, Nauchny Zhurnal "Sodruzhestvo”, 3, Part 2, 105-109 [In Russian].

Pevnev, A. K., 2003, Ways to Practical Earthquake Prediction, Moscow, GEOS [In Russian].

Ramberg, H., 1985, Gravity and Deformation in the Eearth's Crust, Moscow, Nedra [In Russian].

Salnikov, A. S.; Staroseltsev, V. S.; Sobolev, P. N., 2014, Report on the Results of Work on the Object "Creation of the Reference Geological and Geophysical 3 DV Profile (North-Eastern Section)", Rosgeolfond TFGI in the Far East Federal District [In Russian].

Vvedenskaya, A. V., 1984, Seismodynamics, Moscow, Nauka [In Russian]. 